\title{
Identifying Drivers of the Malaysian Economy Using Policy-Relevant Measures
}

\author{
M. Yusof Saari \\ Chakrin Utit ${ }^{\mathrm{b}}$ \\ Nur Adilah Hamidc \\ Ibrahim Kabiru Maji ${ }^{\mathrm{d}}$ \\ Azman Hassan \\ Universiti Putra Malaysia
}

\begin{abstract}
Input-output linkages and multipliers are the two measures that are frequently used to find the drivers of an economy. Deriving from these two measures based on the traditional approach fails to consider the relative sectoral sizes. This paper introduces new linkage and multiplier measures that do not solely adjust for the relative sizes, but also extend the measures for policy-relevant indicators in Malaysia. Comparing the results between the traditional approach and the new approach, there is a clear indication that the former incorrectly identified the drivers of the Malaysian economy. The traditional approach not only introduced bias in linkages, but also overestimated the actual size of the multipliers. The new linkage and multiplier measures that were developed in this paper can be applied for other economies in finding key drivers for specific policy goals.
\end{abstract}

Keywords: Backward linkages, forward linkages, input-output, multipliers, value added JEL classification: C67, D57, 021

\section{Introduction}

In the fields of development and planning economics, input-output analysis was used extensively to determine key sectors of economic drivers. The key sectors of economic drivers were previously identified based on two commonly used measures of linkages and multipliers. Backward and forward linkages measure the level of dependencies of intermediate input purchases and intermediate input sales for a given sector. A sector may have large backward and forward linkages, however, that does not tell policy makers whether that sector is passively receiving impulses from other sectors or actively sending impulses to other sectors. Consequently, the existence of large

a Department of Economics, Faculty of Economics and Management, Universiti Putra Malaysia, 43400 Serdang, Selangor, Malaysia. The author is also attached to the Institute of Agricultural and Food Policy Studies of Universiti Putra Malaysia. E-mail: yusofsaari_upm@upm.edu.my

b Institute of Agricultural and Food Policy Studies, Universiti Putra Malaysia, 43400 Serdang, Selangor, Malaysia. E-mail: chakrin_utit@upm.edu.my (Corresponding author)

c Department of Economics, Faculty of Economics and Management, Universiti Putra Malaysia, 43400 Serdang, Selangor, Malaysia. E-mail: nuradilahhamid@gmail.com

d Department of Economics, Faculty of Economics and Management, Universiti Putra Malaysia, 43400 Serdang, Selangor, Malaysia. E-mail: keibimaji@gmail.com

e Department of Economics, Faculty of Economics and Management, Universiti Putra Malaysia, 43400 Serdang, Selangor, Malaysia. E-mail: azmanhs@upm.edu.my 
backward and forward linkages without further information does not imply that the particular sector can be considered to be a driver of the economy. A second criterion that is based on multipliers must be established. For example, the output multiplier measures the direct and indirect impacts on total output that are potentially generated by each additional unit of the final demand for a particular sector. Therefore, in order to be labelled as a driver sector, in addition to having large linkages to pass on growth impulses, a sector also needs to generate its own growth impulses.

In the Malaysian context, all studies that we reviewed (see Section 2) calculated the linkages and multipliers using the traditional approach. For policy-relevant analysis, the traditional linkage and multiplier measures have two limitations. Firstly, linkages and multipliers were derived without considering the relative size of sectors, and thus may overestimate or underestimate the linkages and multipliers. However, the current literature on input-output analysis emphasised the importance of adjusting the linkages and multipliers according to sectoral sizes (see Oosterhaven \& Stelder, 2002; Dietzenbacher, 2005; Temurshoev \& Oosterhaven, 2014). Secondly, the backward and forward linkages were predominantly measured in terms of gross output and may not provide a clear indication to the level of dependencies for the domestic economy. This is because a sector with strong output linkages does not necessarily have strong value added linkages if the sector is associated with higher leakages (i.e. imports). Therefore, for policy-relevant measures, the linkages and multipliers must be adjusted for the relative sizes of the economic sectors. Furthermore, the linkages must also be extended beyond the gross output and include other indicators, such as value added, which is more relevant for an economic growth policy assessment.

The purpose of this paper is to identify the drivers for the Malaysian economy by developing new linkage and multiplier measures that are more relevant for policy purposes. Therefore, this paper offers two main contributions to the existing literature. Firstly, it is the first attempt to apply multiplier and linkage measures that take into account the relative sectoral sizes in Malaysia. Secondly, we further extend the multiplier and linkage methodologies for growth policy-relevant measures by concentrating on the value added instead of output. In order to run the models, the latest input-output table with a 2010 base year was used for analysis. The results were comparable between the traditional approach and the new approach, as well as verifying the biases in measuring linkages and multipliers.

This paper is structured into five sections. Section 2 reviews the traditional methodologies in measuring linkages and multipliers, with an emphasis on their limitations. Section 3 discusses the new methodology, which adjusts for sizes and extends the linkage and multiplier measures for policy-relevant variables. Section 4 compares the results from the two methodologies. Finally, Section 5 provides concluding remarks.

\section{Multiplier and Linkages: Size Does Matter}

Linkages and multipliers are the two most popular measures that are used by academicians as well as planning and research institutes in order to determine drivers for the Malaysian economy. Previous studies, such as Rashid and Jan (2002), Bekhet (2010), Azmi, Poo and Salleh (2012), Saari, Alias and Chik (2013), and Penang Institute (2015) 
measured linkages in terms of gross output. However, in order to be more relevant for policy formulation, the linkages should be analysed using measures that reflect the main policy goals. For example, an analysis of value added linkages may be more appropriate to be used in planning towards becoming a high income nation by 2020. In the field of linkages, the current literature shows that applications of environmental measures were widely used in examining environment-related policies (see for example, Morán \& González, 2007; Liu \& Wang, 2015). In addition to that, all of the studies that were mentioned above did not adjust for the different sectoral sizes in the linkage measures.

In contrast to the linkage measures, the multiplier measures were used to calculate not only gross output, but also income, value added and employment (see Penang Institute, 2015; Sauian, Kamaruddin, \& Rani, 2004; Puasa \& Radam, 2007; Bekhet, 2011; Fuad \& Puasa, 2011; Mazumder, Ahmed, \& Raquib, 2011; Hassan \& Jenggie, 2012). The multipliers were calculated for the overall sector, as well as on selected sectors, such as education, tourism, agriculture, transportation, finance, and the National Key Economic Areas (NKEA). However, all studies that were mentioned above did not consider the difference in sectoral sizes. We will explain in the following discussion why sizes matter. It is also important to note that emphasising output linkages without considering sectoral sizes are common in most studies involving other countries (see Sabiroglu \& Bashirli, 2012; Morrissey \& O’Donoghue, 2013 for multipliers, and Cristóbal \& Biezma, 2006; Chun et al., 2014 for linkages).

In regard to discussing the limitations of the traditional approach in measuring linkages and multipliers, the following aggregated input-output table for the year 2010 (Table 1) was used to illustrate. In this input-output table, there are five aggregated sectors: agriculture (agr), mining and quarrying (min), manufacturing (man), construction (con), and services (ser). Final demand is aggregated in one category, while primary inputs are separated between value added and imports. Panel A presents the inputoutput flows, expressed in billions of Malaysian ringgit (RM). In the input-output table, row $(i)$ indicates the intermediate and primary inputs purchased by each sector, while column $(j)$ shows sales of output to other sectors as intermediate demands and final demand. The relationship between the sectors can be represented by the following expressions. ${ }^{1}$

$$
\mathbf{x}=\mathbf{Z i}+\mathbf{f}
$$

The matrix $\mathbf{Z}$ denotes the intermediate deliveries, while each element of $z_{i j}$ indicates the amount of commodities sector $i$ used by sector $j$. The vector $f$ represents the final demand. Summing across the columns, the total gross output throughout the economy, $\mathbf{x}$ can be found in equation (1). The same value of input (since $\mathbf{x}^{\prime}=\mathbf{x}$ ) can be found by summing across the rows, as represented by Equation (2).

$$
x^{\prime}=i^{\prime} Z+v+m
$$

\footnotetext{
For clarity, matrices are indicated by bold, upright capital letters; vectors by bold, upright lower case letters; and scalar by italicised lower case letters. Vectors are columns by definition, therefore, that row's vectors are obtained by transposition, indicated by a prime (e.g. $\left.\mathbf{x}^{\prime}\right)$. A diagonal matrix with the elements of vector $x$ on its main diagonal and all other entries equal to zero are indicated by a circumflex (e.g. $\hat{\mathbf{x}}$ ). A summation vector is represented by $\mathbf{i}$.
} 
The vector $\mathbf{v}$ shows the value added and the vector $\mathbf{m}$ gives the sectoral imports. Equations (1) and (2) are simply two alternative ways of summing all of the elements in the table.

For linkages, the backward and forward measures were calculated based on the Leontief inverse matrix and the Ghosh inverse matrix, respectively. Panels B and C provide the Leontief and Ghosh inverse matrices. In the Leontief inverse matrix, the

Table 1. Simplified input-output table for Malaysia in 2010

\begin{tabular}{|c|c|c|c|c|c|c|c|}
\hline & Agr & Min & Man & Con & Ser & $\begin{array}{c}\text { Final } \\
\text { demand }\end{array}$ & $\begin{array}{c}\text { Total } \\
\text { output }\end{array}$ \\
\hline \multicolumn{8}{|c|}{ A. Input-output transactions (RM billion) } \\
\hline Agriculture (Agr) & 6.04 & 0.00 & 28.06 & 0.09 & 6.31 & 14.57 & 55.07 \\
\hline Mining and quarrying (Min) & 0.00 & 0.09 & 31.35 & 1.22 & 3.09 & 51.15 & 86.90 \\
\hline Manufacturing (Man) & 5.28 & 4.11 & 204.38 & 16.99 & 60.81 & 493.42 & 784.98 \\
\hline Construction (Con) & 0.00 & 1.19 & 5.89 & 0.34 & 16.80 & 37.15 & 61.36 \\
\hline Services (Ser) & 5.56 & 10.18 & 118.82 & 11.17 & 191.83 & 278.04 & 615.60 \\
\hline Value added & 34.04 & 67.13 & 141.74 & 16.19 & 262.33 & & \\
\hline Imports & 4.15 & 4.20 & 254.74 & 15.36 & 74.44 & & \\
\hline Total input & 55.07 & 86.90 & 784.98 & 61.36 & 615.60 & & \\
\hline \multicolumn{8}{|l|}{ B. Leontief inverse matrix } \\
\hline Agriculture (Agr) & 1.133 & 0.006 & 0.061 & 0.024 & 0.027 & & \\
\hline Mining and quarrying (Min) & 0.008 & 1.006 & 0.059 & 0.040 & 0.017 & & \\
\hline Manufacturing (Man) & 0.178 & 0.099 & 1.416 & 0.438 & 0.224 & & \\
\hline Construction (Con) & 0.007 & 0.020 & 0.021 & 1.020 & 0.044 & & \\
\hline Services (Ser) & 0.208 & 0.199 & 0.336 & 0.376 & 1.520 & & \\
\hline Total & 1.535 & 1.331 & 1.892 & 1.897 & 1.832 & & \\
\hline \multicolumn{8}{|l|}{ C. Ghosh inverse matrix } \\
\hline Agriculture (Agr) & 1.133 & 0.005 & 0.012 & 0.006 & 0.019 & & \\
\hline Mining and quarrying (Min) & 0.010 & 1.006 & 0.011 & 0.028 & 0.028 & & \\
\hline Manufacturing (Man) & 0.866 & 0.530 & 1.416 & 0.265 & 0.428 & & \\
\hline Construction (Con) & 0.026 & 0.028 & 0.034 & 1.020 & 0.037 & & \\
\hline Services (Ser) & 0.297 & 0.124 & 0.176 & 0.438 & 1.520 & & \\
\hline Total & 2.332 & 1.694 & 1.650 & 1.757 & 2.033 & & \\
\hline \multicolumn{8}{|c|}{ D. Linkages and multipliers - traditional approach } \\
\hline Output-backward linkage & 0.904 & 0.784 & 1.115 & 1.117 & 1.079 & & \\
\hline Output-forward linkage & 1.232 & 0.895 & 0.871 & 0.928 & 1.074 & & \\
\hline Output multiplier & 1.535 & 1.331 & 1.892 & 1.897 & 1.832 & & \\
\hline \multicolumn{8}{|c|}{ E. Linkages and multipliers - adjusted for sizes } \\
\hline Output-backward linkage & 0.406 & 0.784 & 1.189 & 1.148 & 0.827 & & \\
\hline Output-forward linkage & 1.618 & 1.390 & 0.833 & 0.903 & 1.112 & & \\
\hline Output multiplier & 0.026 & 0.078 & 1.068 & 0.081 & 0.583 & & \\
\hline
\end{tabular}

Source: Panel A was obtained from the Department of Statistics Malaysia (2014) and Panels B-E were calculated by the authors. 
interdependencies among the production sectors can be shown based on the following material balance equation,

$$
x=A x+f
$$

where $\mathbf{x}$ is the vector for gross output, $\mathbf{A}\left(\mathbf{A}=\mathbf{Z} \hat{\mathbf{x}}^{-\mathbf{1}}\right)$ is known as the technical coefficient or input-output coefficient, while $\mathbf{f}$ is the vector for final demand. In the standard Leontief model, equation (3) can be transformed and solved in a matrix notation as follows,

$$
\mathbf{X}=(\mathbf{I}-\mathbf{A})^{-1} \mathbf{f}=\mathbf{L f}
$$

where $\mathbf{I}$ is the identity matrix, and $(\mathbf{I}-\mathbf{A})^{-1}$ is known as the Leontief inverse matrix or the multiplier matrix. Each element of the Leontief inverse matrix shows total output effects (both the direct and indirect effects) for any sector $j$ to satisfy each unit of final demand. The Leontief model is essentially a demand-driven model, where the exogenous final demand determines the output and supply variables, such as value added and imports.

In contrast to the Leontief model, the Ghosh model is a supply-driven model, where variables of value added and imports are the exogenous components, while the final demands are endogenously determined. It provides an alternative interpretation that relates to sectoral gross production to the primary inputs, which is to a unit of value entering the inter-industry system at the beginning of the production process. Technically, the supply-driven model operates by 'rotating' or transposing the vertical (column) view of the model to a horizontal (row) view. The Ghosh model can be summarised as follows:

$$
\mathbf{x}^{\prime}=\mathbf{i}^{\prime} \hat{\mathbf{x}} \mathbf{B}+\mathbf{d}^{\prime}=\mathbf{x}^{\prime} \mathbf{B}+\mathbf{d}^{\prime}
$$

where $\mathbf{i}^{\prime} \hat{\mathbf{x}}=\mathbf{x}^{\prime}, \mathbf{B}\left(\mathbf{B}=\hat{\mathbf{x}}^{-1} \mathbf{Z}\right)$ represents the output coefficient matrix and $\mathbf{d}^{\prime}$ is the vector of primary inputs (i.e. value added and imports). Each element of the matrix output coefficient shows the delivery $z_{i j}$ of commodity sector $i$ to sector $j$ per unit of the seller's output. The solution for (5) is:

$$
\mathbf{X}^{\prime}=\mathbf{d}^{\prime}(\mathbf{I}-\mathbf{B})^{-1}=\mathbf{d}^{\prime} \mathbf{G}
$$

Based on the Leontief and Ghosh inverse matrices in Panels B and C, we calculate the backward and forward indices for output as follows:

$$
\begin{aligned}
& B_{i}=\left((1 / n) \Sigma_{i} I_{i j} /\left(1 / n^{2}\right) \Sigma_{i} \Sigma_{j} l_{i j}\right) \quad \text { for backward linkages } \\
& F_{i}=\left((1 / n) \Sigma_{j} b_{i j} /\left(1 / n^{2}\right) \Sigma_{i} \Sigma_{j} b_{i j}\right) \text { for forward linkages }
\end{aligned}
$$

where $I_{i j}$ indicates an element of the Leontief inverse matrix and $b_{i j}$ represents an element of the Ghosh inverse matrix. In previous literature, linkages in Malaysia were 
measured using equations (7) and (8) (see for example, Rashid \& Jan, 2002; Bekhet, 2010; Azmi et al., 2012). For both equations, the first term on the right-hand side is multiplied by $(1 / n)$ to get the average response of backward and forward linkages to an increase in demand and supply. The second term on the right-hand side represents the average of the backward and forward linkage effects relative to the total economy. Calculation results are presented in Panel D. If the values of both forward and backward linkages are greater than one for a particular sector, it implies that the sector plays a significant role in national economic development by supporting (forward linkage effects) as well as boosting (backward linkage effects) other sectors.

In Panel D, we also calculate the output multiplier based on the Leontief model.

$$
t_{i}=\Sigma_{i} I_{i j}
$$

Specifically, the output multiplier for each sector is simply equal to the summation of the Leontief inverse matrix along the rows. It is important to note that the Leontief model was used extensively in the literature whereas the application of the Ghosh model was very limited. In many cases, the Ghosh model was implausible (see Oosterhaven, 1996; Dietzenbacher, 1997; Miller \& Blair, 2009), therefore, we will not discuss an analysis of the Ghosh model.

From the assessment of the linkages and multipliers, the results in Panel D clearly show the importance of the construction sector in the Malaysian economy. The backward linkage effect for this sector is 1.117 and the forward linkage effect was closer to one at 0.928 , indicating the potential of the construction sector in booming and supporting other sectors. The output multiplier measures the impact on output for each additional unit of the final demand. Results for the output multiplier clearly show that the construction sector has the largest impact on the economy. Therefore, this method suggests that policy makers should consider the construction sector to be the key sector or driver of the Malaysian economy.

In regard to policy, linkage and multiplier measures in Panel D are less relevant. For multipliers, analysing the effect of a one-unit increase in the final demand may be less appropriate in policy contexts. It is implicitly assumed that the policy cost of stimulating growth is equal for all sectors. This may not be realistic because a one-unit increase usually requires more efforts in a smaller sector than it does in a large sector (Dietzenbacher, 2005). The conflicting implication between the multipliers and the actual contribution of the construction sector can be clearly observed in Panel $D$ and Panel A. Moreover, the total output multiplier for the construction sector is the highest, however, this sector contributes only 3.83 percent to the total output of the economy. This shows that the relative size of sectors is a matter to be considered when deriving linkage and multiplier measures.

Linkage and multiplier measures in Panel $E$ were calculated by taking into account the relative size of sectors. From Temurshoev and Oosterhaven (2014), the linkage and backward measures that were adjusted for sizes can be summarised as follows:

$$
\begin{array}{ll}
\tilde{B}_{i}=\sum_{i} l_{i j}\left(f_{i} / x_{i}\right) & \text { for backward linkages } \\
\tilde{F}_{i}=\sum_{j} b_{i j}\left(d_{i} / x_{i}\right) & \text { for forward linkages }
\end{array}
$$


Following Miller and Blair (2009), the output multipliers that are adjusted for sectoral sizes can be derived as follows:

$$
\tilde{\mathbf{L}}=\mathbf{L}\left\langle\mathbf{f}\left\langle\mathbf{i}^{\prime} \mathbf{f}\right\rangle^{-1}\right\rangle \mathbf{i}
$$

where $\left\langle\mathbf{f}\left\langle\mathbf{i}^{\prime} \mathbf{f}\right\rangle^{-1}\right\rangle \mathbf{i}$ is a diagonal matrix showing each sector's final demand as a proportion of the total final demand, $f_{i} / \Sigma_{i} f_{i}$ is a measure of relative sectoral sizes. Therefore, Equation (12) shows the effect on a sector's output due to a \$1 increase in final demand, which is distributed across sectors according to their proportion to total final demand. ${ }^{2}$

Estimations for Equations (10), (11) and (12) are presented in Panel E. Results show that the manufacturing sector was a key sector or a driver of the Malaysian economy. The magnitude of backward and forward linkages for the manufacturing and construction sectors were comparable. However, the capacity of the manufacturing sector in generating output for each \$1 increase in final demand was 13 times larger than that of the construction sector. Furthermore, the multipliers that were adjusted for sectoral sizes have a good feature in that their summation (across sectors) was equal to the total impact on the whole economy. Therefore, the results in Panel D and Panel E clearly indicate the importance of relative sectoral sizes in deriving the linkage and multiplier measures. The linkage and multiplier measures that do not consider relative sectoral sizes may lead to inaccurate policy decisions. The next section of this paper further develops the linkage and multiplier measures that can be extended beyond the output analysis.

\section{Policy-relevant Linkage and Multiplier Measures}

The standard linkage measures in Equations (7) and (8) have a limitation in that they can only measure output-linkages. An extension of the measures for other policy-relevant variables, such as value added requires further development of the methodology. In this study, we applied the hypothetical extraction method (HEM) that was predominantly used in the current linkage literature (see for example, Guerra \& Sancho, 2010; Saari et al., 2013; Wang et al., 2013; Ali, 2015; Zhao, Y., Zhang, Z., Wang, S., Zhang, Y., \& Liu, Y., 2015). There are two main advantages of using this technique. Firstly, it is able to explicitly quantify the degree of interdependencies among sectors in monetary and index forms. Secondly, it can be extended to measure not only output-linkages, but also other variables, such as value added, income generation, employment and $\mathrm{CO}_{2}$ emission. Therefore, results from the HEM are highly useful for policy purposes.

The central idea of HEM is that the hypothetical elimination of a complete sector in the economic system allows for estimating an economy-wide contribution of a particular sector (for an overview, see Temurshoev \& Oosterhaven, 2014). By leaving the technical production process in a variant, it is thus assumed that the inputs required for the production are no longer delivered by the sector within the system, but has its origin outside the system. For backward linkages, HEM nullifies the $i$-th column of

2 This type of multiplier is called 'growth equalised' multiplier in Miller and Blair (2009). 
the input coefficient matrix, denoted by $\mathbf{A}^{-i}$, and nullifies the $i$-th element of the final demand vector, denoted by $\mathbf{f}^{-i}$. As a consequence of this nullifying process, the vector of total output after extracting sector $i$ is given by:

$$
\mathbf{x}_{l}^{-i}=\mathbf{L}^{-i} \mathbf{f}^{-i} \text { with } \mathbf{L}^{-i}=\left(\mathbf{I}-\mathbf{A}^{-i}\right)^{-1}
$$

For forward linkages, HEM nullifies the $i$-th row of the output coefficient matrix, denoted by $\mathbf{B}^{-i}$, and nullifies the $i$-th element of the primary input vector, denoted by $\mathbf{d}^{-i}$. Therefore, the total input after extracting sector $i$ is given by:

$$
\mathbf{x}_{b}^{-i}=\left(\mathbf{d}^{-i}\right)^{\prime} \mathbf{G}^{-i} \text { with } \mathbf{G}^{-i}=\left(\mathbf{I}-\mathbf{B}^{-i}\right)^{-1}
$$

The normalised backward and forward linkages due to the complete extraction can be derived as follows:

$$
\dot{B}_{i}=\frac{\mathbf{i}^{\prime} \mathbf{x}-\mathbf{i}^{\prime} \mathbf{x}_{l}^{-i}}{x_{i}} \quad \text { and } \quad \dot{F}_{j}=\frac{\mathbf{x}^{\prime} \mathbf{i}-\left(\mathbf{x}_{b}^{-i}\right)^{\prime} \mathbf{i}}{x_{i}}
$$

where $\mathbf{i}^{\prime} \mathbf{x}-\mathbf{i}^{\prime} \mathbf{x}_{l}^{-i}$ and $\mathbf{x}^{\prime} \mathbf{i}-\left(\mathbf{x}_{b}^{-i}\right)^{\prime} \mathbf{i}$ represent the total output and total input after extraction of the sector $i$.

For a more policy-oriented analysis, Equations (13) through (15) can be further extended in a generalised form, taking into account specific variables, such as value added, tax and employment. If the policy direction is to maximise the economic growth, the linkage and multiplier measures must be calculated for value added instead of output. The use of an output measure may misguide policy decisions because a higher output multiplier does not necessarily imply a higher value added if the sectors highly depend on imported inputs. To verify this argument, we calculate value added and output multipliers in Appendix 1. For the Office, Accounting, and Computing Machinery sector (Sector 69), the value added multiplier, which is calculated based on the traditional approach, is 0.332 or 25 percent of the total output multiplier of 1.349 . This is in contrast to the Paddy sector (Sector 1), in which the value added multiplier is 0.920 or 79 percent of the total output multiplier of 1.171 . Clearly, determining sector importance based on output measure is misleading and therefore, this paper extends the linkage and multiplier measures for value added indicator.

To illustrate the extended measures, the value added coefficient will be defined as $\pi$, indicating the value added per unit of output produced. In matrix form, the value added coefficient can be expressed as $\hat{\boldsymbol{\pi}}=\hat{\mathbf{v}} \hat{\mathbf{x}}^{-1}$, where value added is formed in a diagonal matrix. We can simply derive the backward and forward linkage measures for value added as follows:

$$
B_{i}=\frac{\mathbf{i}^{\prime} \mathbf{v}-\mathbf{i}^{\prime} \mathbf{v}_{l}^{-i}}{v_{i}} \quad \text { and } \quad \dot{F}_{i}=\frac{\mathbf{v}^{\prime} \mathbf{i}-\left(\mathbf{v}_{b}^{-i}\right)^{\prime} \mathbf{i}}{v_{i}}
$$

where $v_{i}=\pi_{i} x_{i}, \mathbf{v}_{I}^{-i}=\hat{\pi} \mathbf{L}^{-i} \mathbf{f}^{-i}$ and $\mathbf{v}_{b}^{-i}=\left(\mathbf{d}^{-i}\right)^{\prime} \mathbf{G}^{-i} \hat{\pi}$. Furthermore, the generalised form of Equation (16) can be extended to other policy-relevant variables. 
Equation (12) in Section 2 provides an extension for the output multiplier that takes into account the relative sectoral size. The value added multipliers, which are adjusted for relative sectoral sizes, is straightforward and can be expressed as follows:

$$
\mathbf{v}^{\prime}=\boldsymbol{\pi}^{\prime} \mathbf{L}\left\langle\mathbf{f}\left\langle\mathbf{i}^{\prime} \mathbf{f}\right\rangle^{-1}\right\rangle \mathbf{i}=\boldsymbol{\pi}^{\prime} \mathbf{L} \hat{\mathbf{f}}
$$

It is also important to note that the final demand vector, $\mathbf{f}$, consists of private consumption, government consumption, investment and exports. Therefore, Equation (17) has a unique feature that can be further extended to account for the multiplier impact of a specific final demand component on the value added. We are able to determine the sectors with the highest multiplier impact on value added for each \$1 increase in exports, private consumption, and so on.

The next section discusses the main results from the analyses, aiming at determining the drivers of the Malaysian economy. A comparison between the results from the traditional approach and the new approach are also provided. Analyses were run by using the latest input-output table from 2010, published by the Department of Statistics Malaysia (2014), comprising of 124 sectors that were grouped by the Malaysia Standard Industrial Classification 2008 (Department of Statistics Malaysia, 2008).

\section{Empirical Findings}

Recall that in Section 2, the linkage and multiplier measures for output using the traditional approach and the new approach were calculated. The linkage and multiplier measures were calculated based on an aggregated input-output table that consists of five main sectors (agriculture, mining and quarrying, manufacturing, construction and services). These sectoral breakdowns are consistent with the sectoral grouping in the Eleventh Malaysia Plan, 2016-2020 (see Economic Planning Unit, 2015). Analyses in Section 2 clearly show the differences between the traditional approach and new approach in finding drivers for the economy. For all sectors, the traditional multiplier overestimates the actual impacts on output. This also holds for the 124 individual sectors as shown in Appendix 1.

In regard to policy, the traditional approach incorrectly determines the driver of the economy. The output multiplier derived from the traditional approach implicitly assumes that the size of all sectors is equal. The multiplier was interpreted to be the economy-wide impact on output for each $\$ 1$ increase in final demand for each sector. The impact of a $\$ 1$ increase in final demand for the construction sector differs from the impact generated by a similar increase in the final demand for the manufacturing sector, depending on the size of the final demand. Panel A in Table 1 shows that the share of the final demand for the construction sector to the total final demand was 4.2 percent compared to 56.4 percent for the manufacturing sector. The relatively smaller share of final demand for the construction sector explains why a growth-promotion policy is likely to have an insignificant impact on the rest of the economy.

In determining the drivers of the Malaysian economy, the policy variables should be targeted on the value added instead of output for two main reasons. Firstly, sectors with higher output linkages are not necessarily associated with higher value-added linkages. The output measure also includes imports, and therefore, sectors that are 
associated with higher leakages imply a lower value added (although output linkages are higher). Secondly, the current government development plans have emphasised on the promotion of high value-added activities that may help in achieving the targeted growth. Analysing the value-added linkages can provide useful information for policy makers in Malaysia.

Table 2 presents the backward and forward linkages for value added in five aggregated sectors that were calculated based on the new approach. The results for the 124 sectors in detail are provided in Appendix 1. However, these results could not be compared with the traditional approach because the model [see Equations (7) and (8)] was developed only for output linkages, while an extension for value added linkages require an expansion of the current methodology, which is beyond the scope of this paper.

Recall that if the values of both forward and backward linkages are greater than one for a particular sector, this implies that the sector plays a significant role in the domestic economic growth by boosting the value added of other sectors (backward linkages) and supporting the value added of other sectors (forward linkages). Alternatively stated, a backward linkage index above 1 implies that the value added of the rest of the sectors is more dependent on a particular sector compared to the dependency of the sector on the rest of the sectors. The reverse situation is applied for forward linkages. The results in Columns 1 and 2 of Table 2 indicate that the manufacturing and construction sectors have the strongest backward and forward linkages. This implies that the value added generated in the agriculture, mining and quarrying, and services sectors are highly dependent on the linkages of the manufacturing and construction sectors.

As previously mentioned in Section 1, higher backward and forward linkages do not inform the causality, but rather indicates the degree of economic integration. The most important information for policy makers is the impact, where the linkage analysis must correspond with the multipliers. Column 3 presents the value added multipliers, indicating the impact on value added that is potentially generated for each $\$ 1$ increase

Table 2. Value added linkages and multiplier

\begin{tabular}{|c|c|c|c|c|c|}
\hline & \multicolumn{3}{|c|}{ New approach } & \multirow{2}{*}{$\begin{array}{l}\text { Value added } \\
\text { multiplier- } \\
\text { traditional } \\
\text { approach } \\
\text { (4) }\end{array}$} & \multirow{2}{*}{$\begin{array}{c}\text { Growth( }^{\mathrm{a}} \\
(2011- \\
2014) \\
\text { (5) }\end{array}$} \\
\hline & $\begin{array}{c}\text { Backward } \\
\text { linkages } \\
\text { (1) }\end{array}$ & $\begin{array}{c}\text { Forward } \\
\text { linkages } \\
(2)\end{array}$ & $\begin{array}{c}\text { Value added } \\
\text { multiplier } \\
\text { (3) }\end{array}$ & & \\
\hline Agriculture & 0.567 & 1.231 & 0.013 & 0.809 & 2.92 \\
\hline Mining and quarrying & 0.737 & 1.024 & 0.052 & 0.886 & 0.24 \\
\hline Manufacturing & 1.871 & 1.209 & 0.265 & 0.470 & 4.88 \\
\hline Construction & 1.684 & 1.507 & 0.023 & 0.540 & 11.23 \\
\hline Services & 0.917 & 0.982 & 0.229 & 0.720 & 6.52 \\
\hline
\end{tabular}

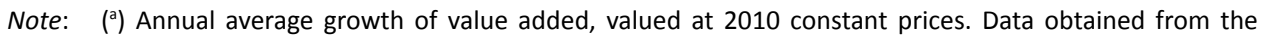
Department of Statistics Malaysia (various years).

Source: Computed from the models. 
in final demand. The results clearly indicate that the manufacturing sector is the driver for the Malaysian economy, by showing the highest degree of interdependencies and associations with the biggest impact on value added. In Appendix 1, the following four sub-sectors show a large contribution to the value added multiplier in the manufacturing sector: oils and fats (0.049); petroleum refinery (0.037); TV, radio receivers, transmitters and related goods (0.030); as well as semi-conductor devices, tubes and circuit boards (0.028). For oils and fats, each $\$ 1$ increase in final demand generates $\$ 0.049$ value added to the total economy, which is equivalent to 19 percent of the total value added multiplier in the manufacturing sector. Therefore, if the results of the traditional approach (see Column 4) are relied upon, it may provide an inaccurate identification of the driver of the economy.

The growth and structural transformation of industrialised Asian economies, such as Japan and South Korea provides strong support for our results. By engaging themselves in manufacturing activities, these countries sustained high growth rates for decades (Rodrik, 2014). In developing countries like China, the manufacturing sector plays a highly significant role with the gross value added recorded in 2013 being equal to 28.9 percent of the GDP (Morrison, 2013). This contribution was relatively higher than the gross value added that was generated in the United States (12.1 percent) and Japan (18.7 percent).

Empirical evidences for developing economies consistently verify the significance of the manufacturing sector to the economic prosperity and should not be neglected since it has its own importance to the economy. Szirmai and Verspagen (2015) found positive impacts of manufacturing growth as the engine of economic growth. However, such effects were not found for the services sector. In addition, Su and Yao (2016) indicate that the manufacturing sector is the major key engine of growth, especially for middle income economies due to its three distinctive characteristics. Firstly, the manufacturing sector has high spillover effects that may bring positive impacts to the growth of other sectors in both the short-run and long-run. Secondly, the development of this sector promotes saving incentives, technological accumulation, and drives the demand for capital and investment. Thirdly, the manufacturing sector intensifies the utilisation of domestic inputs.

Column 5 reports the average annual growth of value added for the period of 20112014. In the Tenth Malaysia Plan (2011-2015), the economy was projected to expand at an average growth rate of 6.0 percent per annum. For the period of 2011-2014, the economy was expected to expand by the average annual growth of 5.3 percent, which was largely driven by the growth in the construction sector at an average growth of 11.2 percent. The construction sector showed a significant contribution to the growth of value added for 2012, 2013 and 2014, which were recorded at 18.1 percent, 10.8 percent and 11.8 percent, respectively. In regard to growth, it may be argued that the targeted growth of the Tenth Malaysia Plan may be achieved by targeting growth on the manufacturing sector.

Equally important, the growth of the Malaysian economy for the period of 20112014 did not depend on the growth of the manufacturing sector because the growth of this sector was largely driven by the performance of exports. Specifically, oils and fats; petroleum refinery; TV, radio receivers, transmitters and related goods; as well 
as semi-conductor devices, tubes and circuit boards exported 72 percent, 69 percent, 93 percent, and 96 percent of their total final output. During this period, the global economy expanded at a moderate and uneven pace as a result of the global financial crisis and oil price shocks. Therefore, the policy recommendation in the Tenth Malaysia Plan to focus on domestic-driven sectors has a strong justification. Among the domestic sectors, growth policy should be directed to the services sector. This is because the backward and forward linkages for the services sector were closer to 1 and its value added multiplier was 10 times larger than the construction sector. The results in Appendix 1 indicate that the wholesale and retail trades and motor vehicles, education, telecommunications, and banking sectors were the service sub-sectors that have significant contributions to the value added multiplier for the services sector.

\section{Concluding Remarks}

Input-output analysis was extensively used in the development and planning to find drivers for the economy. A sector was considered to be a driver of the economy if it demonstrates high backward and forward linkages, as well as having a large multiplier impact. Based on the available literature, previous studies identified the drivers of the Malaysian economy based on the traditional linkage and multiplier measures. In this study, we have shown that the traditional method in measuring linkages and multipliers is biased and fails to consider the relative sectoral sizes. Consequently, the identification of drivers for the economy were likely inaccurate, which in turn, will have a serious implication in designing growth-related policies. In this paper, we introduced new linkage and multiplier measures that adjust for the relative sectoral sizes.

Comparing the results between the traditional and new approaches, there is a clear indication that the former incorrectly identified the drivers of the Malaysian economy. Analyses on five aggregated sectors reveal that the construction sector was considered to be the main driver for the economy based on the traditional approach, while the manufacturing sector was found to be the main driver under the new approach. For the multiplier impacts, the traditional approach overestimated the actual size of the impacts because it implicitly assumes equality in the sectoral sizes. This embodied assumption may not be realistic because a one-unit increase usually requires more efforts in a smaller sector than it does in a large sector. In addition to the relative sectoral sizes, this paper also strongly suggests that the identification of economic growth drivers of the economy should be targeted on the linkage and multiplier measures based on their value-added. The methodologies that were provided in this paper also can be extended for other policy targets, such as tax, employment and income.

This paper also provides a useful methodology to find economic drivers for growth policy planning. The policy cost varies in stimulating different sized sectors, whereby stimulating sectors with low linkage and multiplier impacts will be more costly than stimulating sectors with large linkage and multiplier impacts. However, methodologies developed in this study may be less suitable if the policy interest is to promote growth and development of an infant sector. Essentially, development and promotion of an infant sector requires huge investments and being less connected with the rest of the sectors in the economy. 


\section{References}

Ali, Y. (2015). Measuring $\mathrm{CO}_{2}$ emission linkages with the hypothetical extraction method (HEM). Ecological Indicators, 54, 171-183.

Azmi, R.N.M, Poo, B.T., \& Salleh, N.H.M. (2012). Impak sektor perkhidmatan terhadap ekonomi Malaysia: Pendekatan input-output (Prosiding Persidangan Kebangsaan Ekonomi Malaysia, Ke VII, Jilid 2, pp. 1001-1006). Bangi: Universiti Kebangsaan Malaysia.

Bekhet, H.A. (2010). Ranking sectors changes of the Malaysian economy: Input-output approach. International Business Research, 3(1), 107-130.

Bekhet, H.A. (2011). Output, income and employment multipliers in Malaysian economy: Inputoutput approach. International Business Research, 4(1), 208-223.

Chun, D., Woo, C., Seo, H., Chung, Y., Hong, S., \& Kim, J. (2014). The role of hydrogen energy development in the Korean economy: An input-output analysis. International Journal of Hydrogen Energy, 39(15), 7627-7633.

Cristóbal, J.R.S., \& Biezma, M.V. (2006). The mining industry in the European Union: Analysis of inter-industry linkages using input-output analysis. Resources Policy, 31(1), 1-6.

Department of Statistics Malaysia. (2008). Malaysia Standard Industrial Classification 2008. Putrajaya: Author.

Department of Statistics Malaysia. (2014). Input-output tables Malaysia 2010. Putrajaya: Author.

Department of Statistics Malaysia. (various years). National accounts: Gross domestic product. Putrajaya: Author.

Dietzenbacher, E. (1997). In vindication of the Ghosh model: A reinterpretation as a price model. Journal of Regional Science, 37(4), 629-651.

Dietzenbacher, E. (2005). More on multipliers. Journal of Regional Science, 45(2), 421-426.

Economic Planning Unit. (2015). Eleventh Malaysia plan, 2016-2020: Anchoring growth on people. Putrajaya: Author.

Fuad, S.N.A., \& Puasa, A.F. (2011). National key economic area multiplier impact on Malaysian economy: An input-output analysis. Paper presented at the National Conference on the Tenth Malaysia Plan: Transformation Towards a High Income Advance Economy, Kuala Lumpur.

Guerra A-I., \& Sancho, F. (2010). Measuring energy linkages with the hypothetical extraction method: An application to Spain. Energy Economics, 32(4), 831-837.

Hassan, M.K.H., \& Jenggie, S.T. (2012). The economic impacts of tourism sector on Malaysian economy (Proceedings of BIMP-EAGA Conference 2012, Kota Kinabalu, pp. 1-6). Kota Samarahan: Universiti Malaysia Sarawak (UNIMAS).

Liu, Q., \& Wang, Q. (2015). Reexamine $\mathrm{SO}_{2}$ emissions embodied in China's exports using multiregional input-output analysis. Ecological Economics, 113(May), 39-50.

Mazumder, M.N.H., Ahmed, E.M., \& Raquib, M.A. (2011). Estimating total contribution of tourism to Malaysian economy. International Journal of Business Management and Social Science, 2(3), 29-34.

Miller, R.E., \& Blair, P.D. (2009). Input-output analysis: Foundations and extensions. Cambridge, UK: Cambridge University Press.

Morán, M.A.T., \& González, P.R. (2007). A combined input-output and sensitivity analysis approach to analyze sector linkages and $\mathrm{CO}_{2}$ emissions. Energy Economics, 29(3), 578-597.

Morrison, W.M. (2013). China's economic rise: History, trends, challenges, and implications for the United States. Current Politics and Economics of Northern and Western Asia, 22(4), 461.

Morrissey, K., \& O'Donoghue, C. (2013). The role of the marine sector in the Irish national economy: An input-output analysis. Marine Policy, 37(January), 230-238.

Oosterhaven, J. (1996). Leontief versus Ghoshian price and quantity models. Southern Economic Journal, 62(3), 750-759. 
Oosterhaven, J., \& Stelder, D. (2002). Net multipliers avoid exaggerating impacts: With a biregional illustration for the Dutch transportation sector. Journal of Regional Science, 42(3), 533-543.

Puasa, A.F., \& Radam A. (2007). Agriculture economic multiplier impact on the Malaysian economy: An input-output analysis. In Arshad, F.M., Abdullah, N.M.R., Kaur, B., \& Abdullah, A.M. (Eds.), 50 years of Malaysian agriculture: Transformational issues, challenges and direction (pp. 176-194). Serdang: Universiti Putra Malaysia Press.

Penang Institute. (2015). Higher education as a source of economic growth: Input-output analysis. Retrieved from http://penanginstitute.org/v3/files/research_papers/Higher\%20 Education\%20Report.pdf

Rashid, A.R., \& Jan, S.J. (2002). Linkages and imports of Malaysia, 1978-1987: An input-output approach. Analisis, 9(1\&2), 135-155.

Rodrik, D. (2014). The past, present, and future of economic growth. Challenge, 57(3), 5-39.

Saari, M.Y., Alias, E.F., \& Chik, N.A. (2013). The importance of the agricultural sector to the Malaysian economy: Analyses of inter-industry linkages. Pertanika Journal Social Science and Humanities, 21(September), 173-188.

Sauian, M.S., Kamaruddin, N., \& Rani, R.M. (2004). The importance of transportation and financial sectors in the Malaysian services industries: An input-output analysis. International Proceedings of Economic Development and Research, 43, 135-140.

Sabiroglu, I.M., \& Bashirli, S. (2012). Input-output analysis in an oil-rich economy: The case of Azerbaijan. Resources Policy, 37(1), 73-80.

Su, D., \& Yao, Y. (2016). Manufacturing as the key engine of economic growth for middle-income economies (ADBI Working Paper No. 573). Tokyo, Japan: Asian Development Bank Institute.

Szirmai, A., \& Verspagen, B. (2015). Manufacturing and economic growth in developing countries, 1950-2005. Structural Change and Economic Dynamics, 34(September), 46-59.

Temurshoev, U., \& Oosterhaven, J. (2014). Analytical and empirical comparison of policy-relevant key sector measures. Spatial Economic Analysis, 9(3), 284-308.

Wang, Y., Wang, W., Mao, G., Cai, H., Zuo, J., Wang, L., \& Zhao, P. (2013). Industrial $\mathrm{CO}_{2}$ emissions in China based on hypothetical extraction method: Linkage analysis. Energy Policy, 62(November), 1238-1244.

Zhao, Y., Zhang, Z., Wang, S., Zhang, Y., \& Liu, Y. (2015). Linkage analysis of sectoral $\mathrm{CO}_{2}$ emissions based on the hypothetical extraction method in South Africa. Journal of Cleaner Production, 103(September), 916-924. 
Appendix 1. Output and value added multipliers and linkages

\begin{tabular}{|c|c|c|c|c|c|c|c|}
\hline & & \multicolumn{2}{|c|}{$\begin{array}{l}\text { Output } \\
\text { multiplier }\end{array}$} & \multicolumn{2}{|c|}{$\begin{array}{l}\text { Linkages - } \\
\text { new approach }\end{array}$} & \multicolumn{2}{|c|}{$\begin{array}{l}\text { Value added } \\
\text { multiplier }\end{array}$} \\
\hline & & $\begin{array}{l}\text { Traditional } \\
\text { approach }\end{array}$ & $\begin{array}{c}\text { New } \\
\text { approach }\end{array}$ & Backward & Forward & $\begin{array}{l}\text { Traditional } \\
\text { approach }\end{array}$ & $\begin{array}{c}\text { New } \\
\text { approach }\end{array}$ \\
\hline 1 & Paddy & 1.171 & 0.000 & 0.115 & 1.496 & 0.920 & 0.000 \\
\hline 2 & Food crops & 1.236 & 0.000 & 0.430 & 1.293 & 0.849 & 0.000 \\
\hline 3 & Vegetables & 1.309 & 0.002 & 0.959 & 0.993 & 0.796 & 0.001 \\
\hline 4 & Fruits & 1.238 & 0.003 & 1.019 & 0.941 & 0.889 & 0.002 \\
\hline 5 & Rubber & 1.614 & 0.010 & 1.149 & 0.792 & 0.902 & 0.006 \\
\hline 6 & Oil palm & 1.336 & 0.002 & 0.198 & 1.120 & 0.876 & 0.001 \\
\hline 7 & Flower plants & 1.242 & 0.000 & 0.788 & 1.092 & 0.887 & 0.000 \\
\hline 8 & Other agriculture & 1.200 & 0.000 & 0.633 & 1.201 & 0.901 & 0.000 \\
\hline 9 & Poultry farming & 1.786 & 0.010 & 1.463 & 0.713 & 0.689 & 0.004 \\
\hline 10 & Other livestock & 1.784 & 0.005 & 1.518 & 0.646 & 0.697 & 0.002 \\
\hline 11 & Forestry and logging & 2.101 & 0.005 & 1.008 & 1.415 & 0.734 & 0.002 \\
\hline 12 & Fishing & 1.843 & 0.012 & 1.421 & 0.973 & 0.745 & 0.005 \\
\hline 13 & Crude oil and natural gas & 1.188 & 0.041 & 0.516 & 1.222 & 0.915 & 0.032 \\
\hline 14 & Metal ore mining & 1.351 & 0.001 & 0.487 & 1.367 & 0.859 & 0.000 \\
\hline 15 & Stone clay and sand quarrying & 1.285 & 0.001 & 0.262 & 1.458 & 0.867 & 0.001 \\
\hline 16 & Other mining and quarrying & 1.514 & 0.000 & 0.244 & 2.741 & 0.796 & 0.000 \\
\hline 17 & Meat and meat production & 2.306 & 0.002 & 2.630 & 1.613 & 0.644 & 0.001 \\
\hline 18 & Preservation of seafood & 2.558 & 0.005 & 3.045 & 1.155 & 0.730 & 0.001 \\
\hline 19 & $\begin{array}{l}\text { Preservation of fruits and } \\
\text { vegetables }\end{array}$ & 1.929 & 0.001 & 2.602 & 1.112 & 0.549 & 0.000 \\
\hline 20 & Dairy production & 2.029 & 0.009 & 2.389 & 0.732 & 0.572 & 0.003 \\
\hline 21 & Oils and fats & 2.660 & 0.162 & 9.039 & 1.729 & 0.811 & 0.049 \\
\hline 22 & Grain mills & 1.788 & 0.004 & 2.134 & 0.911 & 0.852 & 0.002 \\
\hline 23 & Bakery products & 1.860 & 0.007 & 1.929 & 0.759 & 0.653 & 0.003 \\
\hline 24 & Confectionery & 1.535 & 0.008 & 1.296 & 1.175 & 0.531 & 0.003 \\
\hline 25 & Other food processing & 1.761 & 0.008 & 1.662 & 0.866 & 0.628 & 0.003 \\
\hline 26 & Animal feed & 1.867 & 0.002 & 2.001 & 2.567 & 0.517 & 0.000 \\
\hline 27 & Wine and spirits & 1.476 & 0.002 & 1.071 & 1.002 & 0.677 & 0.001 \\
\hline 28 & Soft drinks & 1.868 & 0.006 & 2.609 & 0.607 & 0.532 & 0.002 \\
\hline 29 & Tobacco products & 1.345 & 0.002 & 1.138 & 0.895 & 0.796 & 0.001 \\
\hline 30 & Yarn and cloth & 1.867 & 0.003 & 1.921 & 1.262 & 0.570 & 0.001 \\
\hline 31 & Finishing of textiles & 1.968 & 0.002 & 2.597 & 0.550 & 0.614 & 0.001 \\
\hline 32 & Other textiles & 1.660 & 0.002 & 1.529 & 1.127 & 0.554 & 0.001 \\
\hline 33 & Wearing apparel & 1.589 & 0.006 & 1.336 & 0.865 & 0.650 & 0.003 \\
\hline 34 & Leather industries & 1.767 & 0.000 & 1.644 & 0.904 & 0.553 & 0.000 \\
\hline 35 & Footwear & 1.746 & 0.001 & 1.206 & 1.062 & 0.735 & 0.000 \\
\hline 36 & $\begin{array}{l}\text { Sawmilling and planning } \\
\text { of wood }\end{array}$ & 2.438 & 0.005 & 3.212 & 1.555 & 0.720 & 0.001 \\
\hline 37 & $\begin{array}{l}\text { Veneer, plywood, laminated } \\
\text { and particle board }\end{array}$ & 2.513 & 0.013 & 4.926 & 1.765 & 0.654 & 0.003 \\
\hline 38 & $\begin{array}{l}\text { Builders' carpentry and } \\
\text { joinery }\end{array}$ & 2.505 & 0.000 & 2.730 & 2.448 & 0.713 & 0.000 \\
\hline 39 & Wooden and cane containers & 2.601 & 0.000 & 3.013 & 2.183 & 0.738 & 0.000 \\
\hline 40 & Other wood products & 2.284 & 0.001 & 3.239 & 0.754 & 0.690 & 0.000 \\
\hline 41 & $\begin{array}{l}\text { Paper and paper products } \\
\text { and furniture }\end{array}$ & 2.069 & 0.026 & 2.024 & 1.339 & 0.621 & 0.008 \\
\hline
\end{tabular}


Appendix 1. Continued

\begin{tabular}{|c|c|c|c|c|c|c|c|}
\hline & & \multicolumn{2}{|c|}{$\begin{array}{l}\text { Output } \\
\text { multiplier }\end{array}$} & \multicolumn{2}{|c|}{$\begin{array}{l}\text { Linkages - } \\
\text { new approach }\end{array}$} & \multicolumn{2}{|c|}{$\begin{array}{l}\text { Value added } \\
\text { multiplier }\end{array}$} \\
\hline & & $\begin{array}{l}\text { Traditional } \\
\text { approach }\end{array}$ & $\begin{array}{c}\text { New } \\
\text { approach }\end{array}$ & Backward & Forward & $\begin{array}{l}\text { Traditional } \\
\text { approach }\end{array}$ & $\begin{array}{c}\text { New } \\
\text { approach }\end{array}$ \\
\hline 42 & Publishing & 1.639 & 0.000 & 2.323 & 0.723 & 0.418 & 0.000 \\
\hline 43 & Printing & 1.707 & 0.001 & 0.814 & 2.529 & 0.641 & 0.000 \\
\hline 44 & Petroleum refinery & 1.712 & 0.087 & 2.876 & 1.615 & 0.733 & 0.037 \\
\hline 45 & Basic chemicals & 1.975 & 0.028 & 1.224 & 1.410 & 0.644 & 0.009 \\
\hline 46 & Fertilisers & 1.706 & 0.002 & 1.432 & 2.692 & 0.486 & 0.000 \\
\hline 47 & Paints and varnishes & 1.791 & 0.001 & 1.116 & 1.848 & 0.587 & 0.000 \\
\hline 48 & $\begin{array}{l}\text { Pharmaceuticals, chemicals } \\
\text { and botanical products }\end{array}$ & 1.400 & 0.001 & 0.615 & 1.725 & 0.597 & 0.000 \\
\hline 49 & $\begin{array}{l}\text { Soap, detergents, perfumes, } \\
\text { cleaning and toilet } \\
\text { preparations }\end{array}$ & 1.930 & 0.003 & 1.542 & 1.415 & 0.585 & 0.001 \\
\hline 50 & Other chemical products & 2.028 & 0.024 & 3.016 & 1.910 & 0.518 & 0.006 \\
\hline 51 & Tyres & 2.031 & 0.003 & 3.920 & 2.578 & 0.453 & 0.001 \\
\hline 52 & Rubber processing & 2.355 & 0.005 & 3.029 & 2.082 & 0.470 & 0.001 \\
\hline 53 & Rubber gloves & 2.531 & 0.017 & 13.346 & 3.073 & 0.478 & 0.003 \\
\hline 54 & Rubber products & 2.589 & 0.007 & 8.873 & 1.055 & 0.477 & 0.001 \\
\hline 55 & Plastics products & 1.920 & 0.020 & 2.211 & 1.643 & 0.457 & 0.005 \\
\hline 56 & $\begin{array}{l}\text { Sheet glass and glass } \\
\text { products }\end{array}$ & 1.907 & 0.002 & 1.562 & 1.543 & 0.561 & 0.001 \\
\hline 57 & Clay and ceramic & 1.811 & 0.002 & 1.909 & 1.907 & 0.589 & 0.001 \\
\hline 58 & Cement, lime and plaster & 2.077 & 0.001 & 1.954 & 1.946 & 0.747 & 0.000 \\
\hline 59 & $\begin{array}{l}\text { Concrete and other non- } \\
\text { metallic mineral products }\end{array}$ & 2.274 & 0.002 & 3.888 & 3.283 & 0.656 & 0.001 \\
\hline 60 & Iron and steel products & 1.904 & 0.007 & 1.586 & 2.402 & 0.442 & 0.002 \\
\hline 61 & $\begin{array}{l}\text { Basic precious and } \\
\text { non-ferrous metals }\end{array}$ & 1.516 & 0.013 & 2.104 & 1.788 & 0.310 & 0.003 \\
\hline 62 & Casting of metals & 1.770 & 0.000 & 1.017 & 1.915 & 0.584 & 0.000 \\
\hline 63 & Structural metal products & 1.828 & 0.003 & 1.422 & 1.796 & 0.521 & 0.001 \\
\hline 64 & $\begin{array}{l}\text { Other fabricated metal } \\
\text { products }\end{array}$ & 1.739 & 0.013 & 1.421 & 1.432 & 0.498 & 0.004 \\
\hline 65 & Industrial machinery & 1.650 & 0.003 & 1.693 & 0.910 & 0.459 & 0.001 \\
\hline 66 & General purpose machinery & 1.601 & 0.009 & 1.382 & 1.078 & 0.507 & 0.003 \\
\hline 67 & Special purpose machinery & 1.520 & 0.008 & 1.192 & 0.980 & 0.594 & 0.003 \\
\hline 68 & Domestic appliances & 1.564 & 0.005 & 1.714 & 0.794 & 0.454 & 0.001 \\
\hline 69 & $\begin{array}{l}\text { Office, accounting and } \\
\text { computing machinery }\end{array}$ & 1.349 & 0.037 & 1.654 & 0.873 & 0.332 & 0.009 \\
\hline 70 & $\begin{array}{l}\text { Electrical machinery and } \\
\text { apparatus }\end{array}$ & 1.743 & 0.003 & 3.395 & 0.920 & 0.354 & 0.001 \\
\hline 71 & Other electrical machinery & 1.439 & 0.006 & 1.468 & 0.872 & 0.430 & 0.002 \\
\hline 72 & Insulated wires and cables & 1.482 & 0.009 & 3.164 & 1.211 & 0.233 & 0.001 \\
\hline 73 & $\begin{array}{l}\text { Electric lamps and lighting } \\
\text { equipment }\end{array}$ & 1.572 & 0.002 & 1.429 & 0.935 & 0.532 & 0.001 \\
\hline 74 & $\begin{array}{l}\text { Semiconductor devices, } \\
\text { tubes and circuit boards }\end{array}$ & 1.373 & 0.108 & 1.601 & 0.848 & 0.358 & 0.028 \\
\hline 75 & $\begin{array}{l}\text { TV, radio receivers and } \\
\text { transmitters \& asso. goods }\end{array}$ & 1.273 & 0.080 & 1.262 & 0.878 & 0.476 & 0.030 \\
\hline
\end{tabular}


Appendix 1. Continued

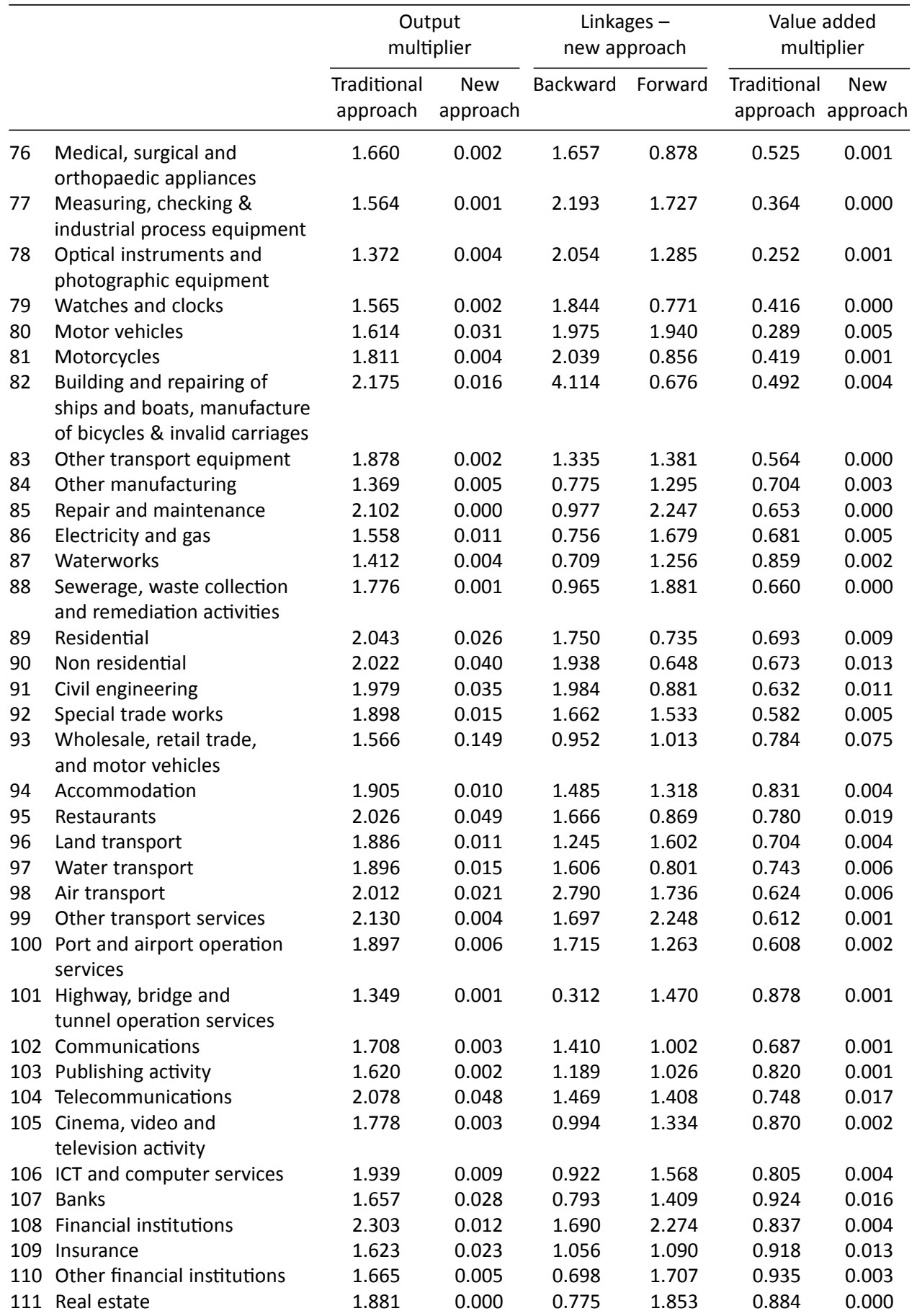


Appendix 1. Continued

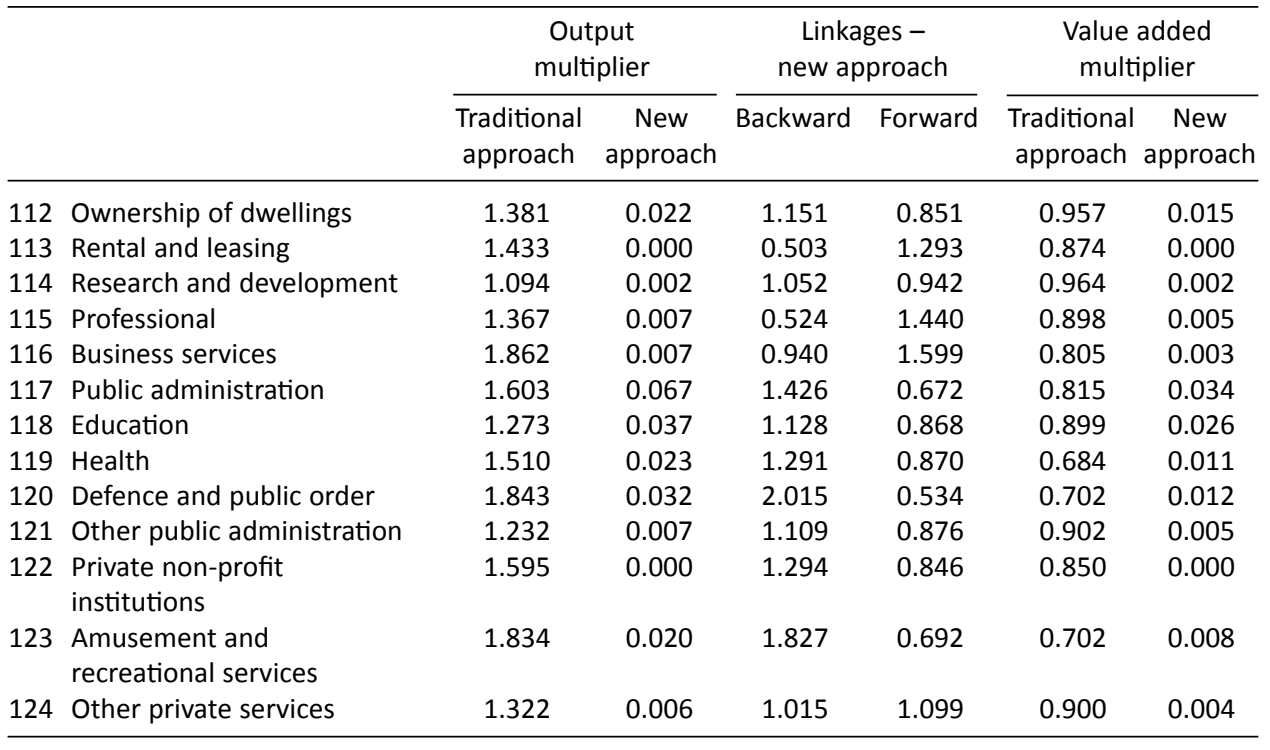

Note: Agriculture (1-12), mining and quarrying (13-16), manufacturing (17-85), construction (89-92) and services $(86-88,93-124)$. 